\title{
EVALUATION OF OZONE CONCENTRATION IN SOFIA, BULGARIA
}

\author{
N. NIKOLOVA, ${ }^{1}$ N. MINTCHEVA ${ }^{2}$
}

\begin{abstract}
Evaluation of ozone concentration in Sofia, Bulgaria. The variability of the concentration of ground level ozone $\left(\mathrm{O}_{3}\right)$ and its relation to the air temperature and wind speed are analysed based on daily and seasonal data from four stations for automatic monitoring of the air quality at the region of Sofia. Three of the stations are situated in the city and one is in the Vitosha Mountain which is located in the vicinity of Sofia, thus a comparison between urban and non-urban sites is pointed out. Data for the period from 2006 to 2015 are analyzed. The average monthly concentrations of the ground level $\mathrm{O}_{3}$ have shown well-defined annual cycle with the highest value in the summer and lowest in the winter. The average seasonal $\mathrm{O}_{3}$ concentrations for the mountainous site, which is located at $1345 \mathrm{~m}$ above sea level, are higher than those for the city stations. The correlation analysis shows good relation between seasonal $\mathrm{O}_{3}$ concentration and wind speed in the winter, as well as positive correlation of air temperature and ozone concentrations in summer and autumn.
\end{abstract}

Keywords: air pollutants, ground level ozone, air temperature, wind speed

\section{INTRODUCTION}

The tropospheric ozone, which is a significant air pollutant and primary constituent of smog, originates from (i) diffusion from the stratosphere into the troposphere and (ii) from photochemical reactions of volatile organic compounds, VOCs and nitrogen oxides, NOx in the presence of air and UV light (Atkinson, 2000). Nitrogen dioxide decomposes under UV radiation to NO and active oxygen, which readily reacts with air oxygen to form ozone:

$$
\begin{aligned}
& \mathrm{NO}_{2} \stackrel{h v}{\rightarrow} \mathrm{NO}+\mathrm{O} \\
& \mathrm{O}+\mathrm{O}_{2} \rightarrow \mathrm{O}_{3}
\end{aligned}
$$

In the absence of VOCs, ozone reacts with $\mathrm{NO}$ to form $\mathrm{NO}_{2}$ and $\mathrm{O}_{2}$ and there is no overall production of ozone.

$$
\mathrm{NO}+\mathrm{O}_{3} \rightarrow \mathrm{NO}_{2}+\mathrm{O}_{2}
$$

However, in the presence of VOCs, NO reacts with organic radicals, formed under UV radiation, and converts to $\mathrm{NO}_{2}$, which then produce $\mathrm{O}_{3}$ by reactions (1) and (2). That's why ozone is considered as a secondary pollutant and its concentration at the ground level strongly depends on the concentrations of primary contaminants, NOx

\footnotetext{
${ }^{1}$ Faculty of Geology and Geography, Sofia University “St. Kliment Ohridski”, Tsar Osvoboditel Blvd. 15, Sofia 1504, Bulgaria, E-mail: nina@gea.uni-sofia.bg

2 Department of Chemistry, University of Mining and Geology, Sofia 1700, Bulgaria, E-mail: nmintcheva@abv.bg
} 
and VOCs, and also of the intensity of solar radiation, which activates photo-assisted reaction (1). Additionally, solar radiation leads to increase of air temperature, and together with other meteorological parameters invoke changes in ozone concentration (Al-Jeelani, 2014; Shao et al., 2009). It was found that the concentration of ozone rises on clear days, when the solar radiation and temperature increase. Many authors reported well-defined diurnal cycle of ozone, showing midday maximum of the ozone concentration due to photochemical transformations producing ozone (Han et al., 2011). The influence of the meteorological parameters, such as air temperature, wind speed, wind direction, relative humidity, pressure, solar radiation, on the variations of $\mathrm{O}_{3}$ concentration at many sites around the world have been studied (Dawson et al., 2007; Wakamatsu et al., 1999; Pudasainee et al., 2006; Rozbicka and Rozbicki, 2014; Filella and Penuelas, 2006). The increased interest to the investigation of ozone concentration in Bulgaria can be seen during the last decades. Donev et al. (2002) investigated the background ozone concentration in the south part of Bulgaria and found that Rojen station (located at $1700 \mathrm{~m}$ a.s.l. in the central Rhodopa mountain) is the best site to estimate the background $\mathrm{O}_{3}$ concentration (average $46-50 \mathrm{ppb}$, equal to $92-100 \mu \mathrm{g} / \mathrm{m}^{3}$ ), while the seacoast site (Ahtopol) has lower values and the mountain-valley site (Ovnarsko) shows higher concentration than the mountain peak site (Rojen). Later on, various relationships of the ozone concentration, aerosols and meteorological parameters at a seacoast site (Ahtopol) were studied by statistical methods (Ivanov et al., 2011). Measurement and analysis of ozone concentration for the period 2007-2009 at two stations situated in Sofia and Plana mountain near-by the city were reported (Tassev et al., 2010). Diurnal, monthly and seasonal trends were observed, where it is worth to mention that the monthly average ozone concentration in the mountain are higher than those in Sofia, as well as the maximum concentration in winter and spring are higher in Plana than in Sofia, while the maximum concentration during summer are slightly higher in Sofia than in Plana. Grigorieva et al. (2012) investigated the surface and total ozone content in the region of Sofia and demonstrated that diurnal ozone cycles had been repeated and similar ozone data had been received every year in the studied 11-year period, if the similar meteorological conditions (solar radiation, temperature, relative humidity, wind speed) in the same season (autumn) were chosen. The reported diurnal ozone variations are typical for urban sites and are characterized by the afternoon ozone maximum and night minimum. They explain the cycle by different dynamic processes: in the morning the solar radiation gradually increases and initiates a vertical transport of the ozone-rich air from aloft to the ground, as well as photochemical formation of ozone from NOx and VOCs, which have both anthropogenic and biogenic origin; in the evening, when the production of ozone is limited by the lack of UV radiation, the concentration of ozone decreases due to its dry deposition on the ground and horizontal or/and vertical air transfer caused by the wind.

Additionally to the above mentioned papers, in this study we emphasize on the seasonal and monthly ground level ozone variations in the region of Sofia for the period 2006 - 2015, consequently we analyze the ozone concentration and 
meteorological data from automatic measurement stations at four different sites across and near-by the city and evaluate their relationships by correlation and regression analysis. In order to achieve the aim of the present paper, the following tacks were solved: 1) investigation of monthly and seasonal distribution of ozone in the urban area and in the mountainous station; 2) assessment of correlation and regression between daily ozone concentration and air temperature or wind speed on seasonal basis.

\section{DATA AND METHODS}

The study is based on the daily average values of the ground level ozone $\left(\mathrm{O}_{3}\right)$ concentrations and daily average air temperatures and wind speed measured in four stations for automatic measurement of the air quality at the region of Sofia. The data are provided by Executive Environment Agency, Bulgaria. Three of the stations are situated in the city - one is in the wide center (station "Hipodruma") and two other stations are in the districts (Nadezhda, and Druzhba). The period involved in the evaluation is from January 2006 to December 2015. The fourth station

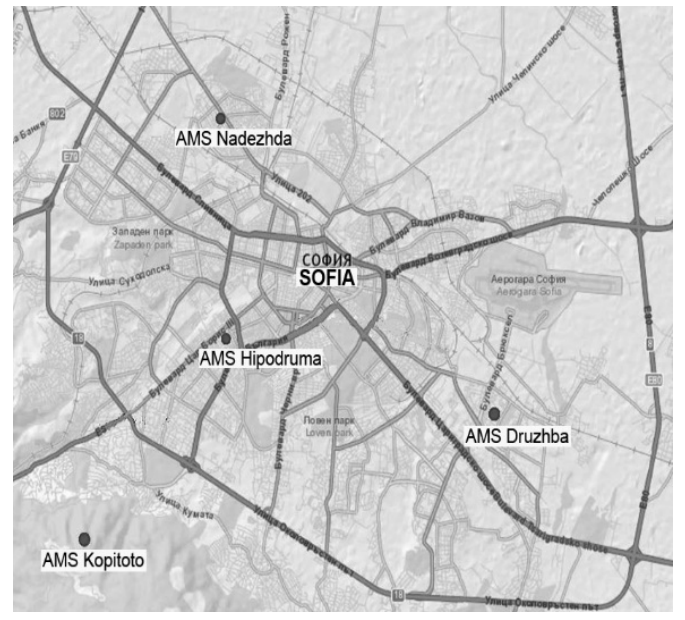

Fig. 1. Location of the stations for automatic measurement of air quality in Sofia "Kopitoto" is situated on the altitude $1345 \mathrm{~m}$ a.s.1 in the Vitosha Mountain which is located near the city of Sofia. Although the data collected on this station are for a shorter period (December 2007 to December 2015), they are used for comparison of ozone content at urban and non-urban places. The location of the stations is presented on Figure 1. The stations are in the frame of the National System for Environmental Monitoring organized by the Executive Environment Agency, Bulgaria.

The relation between the meteorological elements and the ground level ozone concentrations is investigated by correlation analysis for four seasons on the basis of daily data: winter (December - January - February), spring (March - April - May), summer (June July - August) and autumn (September - October - November). Statistical significance of correlation coefficients is tested by t-statistic at level 0.05 . In order to analyse the impact of the air temperature and the wind speed on the ozone concentration, the linear regression is applied. Coefficient of determination $\mathrm{R}^{2}$ (in $\%$ ) is used as a measure of adjustment of regression equation to the empirical distribution of data. 


\section{RESULTS AND DISCUSSIONS}

\subsection{Characteristics of air temperature and wind speed during the period $2006-2015$}

Sofia is a capital of Bulgaria situated in the hollow area between the mountains. The average altitude of the city is $550 \mathrm{~m}$ a.s.l. Climate is moderate continental. The annual average temperature in the analysed stations for the period 2006 - 2015 vary between $11.8{ }^{\circ} \mathrm{C}$ (station Hipodruma) and $10.4{ }^{\circ} \mathrm{C}$ (station Kopitoto). During the winter time the intensive air temperature inversions are observed in the city which is the reason for the lower winter temperature $\left(0.9^{\circ} \mathrm{C}\right.$, station Druzhba) in comparison to the mountain station Kopitoto (Table 1). Summer temperatures are between $19.0{ }^{\circ} \mathrm{C}$ (Kopitoto) and $21.9{ }^{\circ} \mathrm{C}$ in the city. Spring temperatures are a little lower than autumn which is characteristic for the regions with moderate climate.

Table 1. Average daily values of the air temperature and the wind speed

\begin{tabular}{|l|c|c|c|c|c|c|c|c|}
\hline \multirow{2}{*}{$\begin{array}{c}\text { Season } \\
\text { Station }\end{array}$} & winter & spring & summer & autumn & winter & spring & summer & autumn \\
\cline { 2 - 9 } & \multicolumn{6}{|c|}{ Temperature ${ }^{\circ} \mathrm{C}$} \\
\hline Druzhba & 0.9 & 11.3 & 21.8 & 11.9 & 1.8 & 1.8 & 1.4 & 1.5 \\
\hline Nadezhda & 1.1 & 11.6 & 21.9 & 12.1 & 1.1 & 1.1 & 0.9 & 0.9 \\
\hline Hipodruma & 1.4 & 11.7 & 21.9 & 12.2 & 1.2 & 1.2 & 0.8 & 0.9 \\
\hline Kopitoto & 1.8 & 9.1 & 19.0 & 11.7 & 7.9 & 5.4 & 3.2 & 4.3 \\
\hline
\end{tabular}

The average seasonal wind speed is between 0.9 and $1.8 \mathrm{~m} / \mathrm{s}$ in the city and between 3.2 and $7.9 \mathrm{~m} / \mathrm{s}$ in the mountainous station Kopitoto (Table 1). The values of wind speed are higher in winter and spring than in summer and autumn.

The air temperature depends on the solar radiation, which is a crucial factor for UV assisted photochemical reactions that involve ozone, nitrogen oxides and organic compounds. In this study we use the provided data for daily mean air temperatures as an indirect factor affecting the ozone concentration. On the other side, the wind speed and wind direction are meteorological elements that can cause drastic change of the ozone content by dynamic transfer of atmospheric layers, that's why we estimate the correlation wind-ozone concentration as well.

\subsection{Monthly and seasonal distribution of ozone concentration}

Monthly values of the ozone concentrations are calculated as average from daily data for the period 2006 - 2015 except for station Kopitoto (December 2007 December 2015). Annual cycle of monthly values show good synchronicity for all investigated stations (Fig. 2). The maximum is observed in July or August and it corresponds to the maximum of monthly solar radiation and air temperature, which cause enhanced photochemical formation of ozone. The monthly average values in Dec are lowest $\left(19-23 \mu \mathrm{g} / \mathrm{m}^{3}\right)$ for all stations in Sofia city. Similar annual cycle of 
$\mathrm{O}_{3}$ concentrations were also reported by other authors (Han et al., 2011; Dawson et al., 2007). The relative minimum in the annual cycle of ozone concentration is observed in May - June, when the air temperature is high and other factors dominate. We suppose that it is associated with an increase in relative humidity, cloudiness and number of precipitation days, which lead to decrease of ozone levels. The average climate values of the relative humidity for May and June in Sofia are 67-68 \%, while for April the value is $65 \%$ and the minimum in the annual course is observed in July and August (62\%). The precipitation period in Sofia is two days longer in May and June, than the one in April, July and August (Topliiski, 2006). It is well known that rainfall and fog accelerate the deposition of ozone. At higher humidity, the water droplets scatter the sunlight back into space and reduce the solar radiation that reach the surface, that causes decreasing of the ozone concentration (Ivanov et al., 2011).

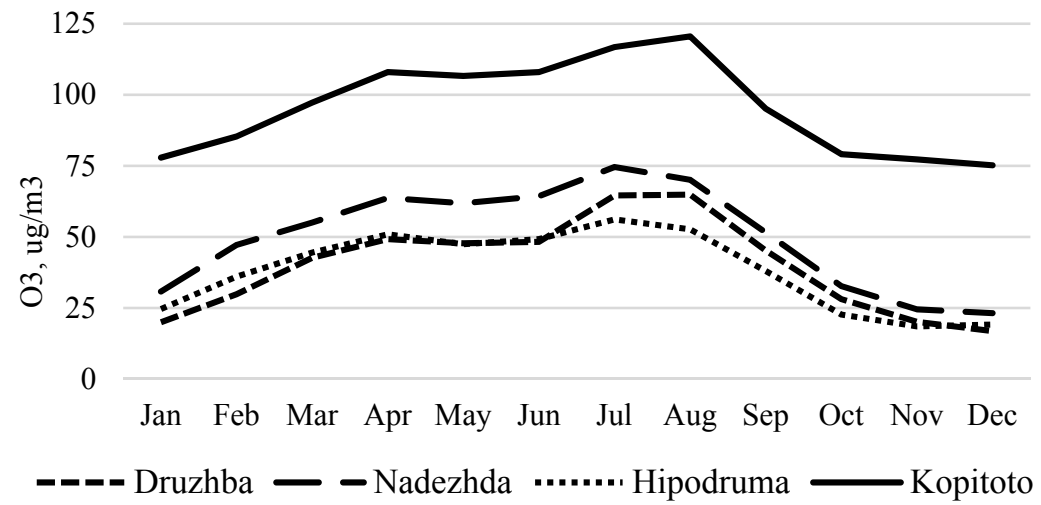

Fig. 2. Monthly values of ground level ozone

The monthly values of $\mathrm{O}_{3}$ concentrations measured at different stations in the city (Druzhba, Nadezhda, Hipodruma) are within a narrow range. The site Nadezhda shows slightly higher values, probably due to the location of the automatic station near the highway. Then additional amount of ozone is generated by photochemical reactions of NOx-rich transport emissions. As can be seen on Fig. 2, the values from mountainous station Kopitoto are twice higher for all over the year. That fact may due to the altitude difference between the city and mountain sites (approx. $800 \mathrm{~m}$ ). The results of the research done by Tassev et al. (2010) show higher ozone concentration in another mountain located nearby the city (Plana Mountain) in comparison to the urban area of Sofia. One natural source of ground level ozone comes from the ozone layer in the lower stratosphere, which descents into the troposphere by atmospheric circulation. We assume that this process accounted for increasing of ozone concentration at higher altitude. The role of the altitude and the orography for the ozone concentration have been shown by Donev et al. (2002), Senik et al. (2005), Rannik et al. (2009). 
Seasonal distribution of the ground level ozone concentration follows monthly data. In all stations the highest concentrations are measured in summer and the values are between 59 and $63 \mu \mathrm{g} / \mathrm{m}^{3}$ in the city and reach $115 \mu \mathrm{g} / \mathrm{m}^{3}$ in station Kopitoto, (Fig. 3). Although spring temperature in urban stations is about $0.6{ }^{\circ} \mathrm{C}$ lower than in autumn (Table 1), the ground level ozone concentration in spring is higher due to multivariable dependence of ozone. Seasonal cycle was observed and reported in previous publications. Rozbicka and Rozbicki (2004) show that ozone concentration in Warsaw agglomeration during summer and spring is about twice higher than one in winter and autumn. Monks (2000) explain the spring ozone maximum with the stratospheric-

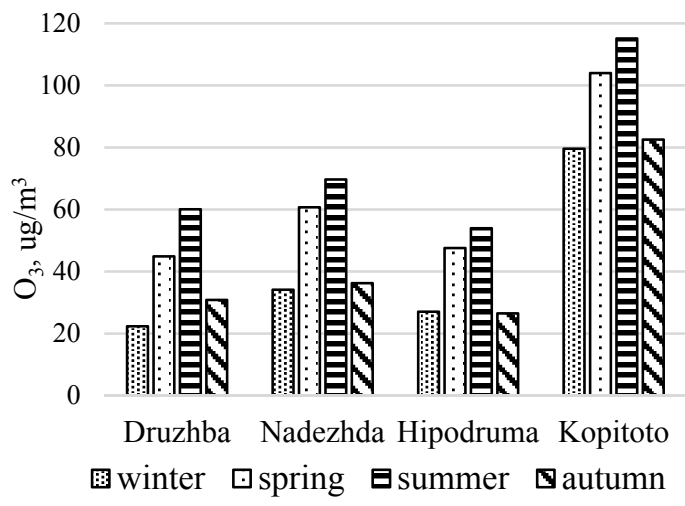

Fig. 3. Seasonal distribution of ground level ozone concentration tropospheric exchange and photochemistry.

The minimal seasonal values are observed in winter and range between 22 and $34 \mu \mathrm{g} / \mathrm{m}^{3}$ for the stations in the city, while the lowest concentration in the mountain is $80 \mu \mathrm{g} / \mathrm{m}^{3}$. Monthly and seasonal values in the urban area and mountain shows that the ozone concentration depends mainly on the physical geographical conditions (such as altitude, orography, temperature and solar radiation) rather than on the anthropogenic activities.

\subsection{Relationship between air temperature, wind speed and ground level ozone concentration}

The air temperature affects the annual trends of pollutants' concentration in the air, through its impact on the atmospheric stability and convection as well as temperature inversions. Temperature inversions reduce the vertical convection, contributing to an increase in the concentration of pollutants in the ground air layer. From other side unsustainable atmospheric stratification in combination with moderate wind could lead to high concentrations of the pollutants.

Correlation analysis show statistically significant positive correlation between ozone and air temperature for summer and autumn (Table 2). Well established relation between air temperature and ozone concentration in urban area is found by Elminir (2005), Kalbarczyk and Kalbarczyk (2009), Rozbicka and Rozbicki, 2014. The low values $(<0.12)$ of correlation coefficients between ozone concentration and air temperature in winter (Table 2) indicate non-significant relationships between both parameters during this season. 
Table 2. Coefficients of correlation and \% of explained variance for the relationship between $\mathrm{O}_{3}$ concentration and air temperature

\begin{tabular}{|l|c|c|c|c|c|}
\hline Station & Coefficients & Winter & Spring & Summer & Autumn \\
\hline \multirow{3}{*}{ Druzhba } & Correlation & -0.06 & 0.22 & $0.63^{*}$ & $0.66^{*}$ \\
\cline { 2 - 6 } & $\begin{array}{c}\text { \% of explained } \\
\text { variance }\end{array}$ & 0.36 & 4.84 & 39.69 & 43.56 \\
\hline \multirow{3}{*}{ Nadezhda } & Correlation & -0.12 & 0.14 & $0.49^{*}$ & $0.63^{*}$ \\
\cline { 2 - 6 } & $\begin{array}{c}\text { \% of explained } \\
\text { variance }\end{array}$ & 1.44 & 1.96 & 24.01 & 39.69 \\
\hline \multirow{2}{*}{ Hipodruma } & Correlation & -0.27 & 0.03 & 0.28 & $0.43^{*}$ \\
\cline { 2 - 6 } & $\begin{array}{c}\text { \% of explained } \\
\text { variance }\end{array}$ & 7.29 & 0.09 & 7.84 & 18.49 \\
\hline \multirow{2}{*}{ Kopitoto } & Correlation & 0.12 & 0.18 & $0.48^{*}$ & $0.59^{*}$ \\
\cline { 2 - 6 } & $\begin{array}{c}\text { \% of explained } \\
\text { variance }\end{array}$ & 1.44 & 3.24 & 23.04 & 34.81 \\
\hline
\end{tabular}

*Marked coefficients are statistically significant at 0.05

In order to estimate the impact of meteorological elements the linear regression equations between ozone concentration (dependent variable) and air temperature and wind speed (independent variables) are used. The highest coefficients of determination ( $\%$ of explained variance) between air temperature and ozone concentration are occurred in autumn and summer (Table 2). The linear regression function explains between 18.49 and $43.56 \%$ the variability of ozone concentration during autumn and between 23.04 and $39.69 \%$ in summer. Exception for summer season is station Hipodruma, where the values of correlation coefficient and $\%$ of explained variance are very low.

Correlation and regression analyses show that the relationship between ground level ozone and wind speed is well determined in winter, when statistically significant correlation coefficients are obtained (Table 3 ). In the city area correlation is positive, while in the mountain it is negative. Despite the lower values of correlation coefficients, the correlation is statistically significant in other seasons as well, with exception of station Druzhba. The positive correlation between wind speed and ozone concentration in urban area can be associated with the impact of sources of the pollution which are located in some distance from the observation place. In this case at the city sites, the increase in average ozone concentration with the increase of wind speed may be caused by transfer of emissions from the pollution sources to the measuring site. Wakamatsu et al. (1999) reported maximum ozone concentration observed further away from the emission area, which results from contaminants transport by the wind.

The percentage of explained variance ranges between 33.64 and $43.56 \%$ in winter season at the urban area (Table 3). This, together with high correlation coefficients discussed above, indicate strong positive dependence of ozone concentration on the wind speed in winter. Similar results were reported by Kalbarczyk and Kalbarczyk (2009) for North-western Poland. Despite of statistically significant correlation coefficients for other three seasons (spring, summer and 
autumn) for stations Hipodruma and Nadezhda, the linear regression functions explain only between 9 and $16 \%$ of the relation between ozone concentration and wind speed.

Table 3. Coefficients of correlation and \% of explained variance for the relationship between $\mathrm{O}_{3}$ concentration and wind speed

\begin{tabular}{|l|c|c|c|c|c|}
\hline Station & Coefficients & Winter & Spring & Summer & Autumn \\
\hline \multirow{3}{*}{ Druzhba } & Correlation & $0.62^{*}$ & 0.18 & 0.14 & 0.17 \\
\cline { 2 - 6 } & $\begin{array}{c}\text { \% of explained } \\
\text { variance }\end{array}$ & 38.44 & 3.24 & 1.96 & 2.89 \\
\hline \multirow{2}{*}{ Nadezhda } & Correlation & $0.66^{*}$ & $0.37^{*}$ & $0.30^{*}$ & $0.32^{*}$ \\
\cline { 2 - 6 } & $\begin{array}{c}\text { \% of explained } \\
\text { variance }\end{array}$ & 43.56 & 13.69 & 9.00 & 10.24 \\
\hline \multirow{2}{*}{ Hipodruma } & Correlation & $0.58^{*}$ & $0.40^{*}$ & $0.30^{*}$ & $0.34^{*}$ \\
\cline { 2 - 6 } & $\begin{array}{c}\text { \% of explained } \\
\text { variance }\end{array}$ & 33.64 & 16.00 & 9.00 & 11.56 \\
\hline \multirow{2}{*}{ Kopitoto } & Correlation & $-0.41^{*}$ & $-0.31^{*}$ & 0.01 & $-0.29^{*}$ \\
\cline { 2 - 6 } & $\begin{array}{c}\text { \% of explained } \\
\text { variance }\end{array}$ & 16.81 & 9.61 & 0.01 & 8.41 \\
\hline
\end{tabular}

*Marked coefficients are statistically significant at 0.05

At the non-urban area the percentage of explained variance is lower $(0.01$ $16.81 \%$ at Kopitoto). The negative relation between the ozone concentration and wind speed is clearly determined in the winter at the mountainous station, when the linear regression function explains $16.81 \%$ of the variation. The opposite sign of the correlation coefficients for all seasons, except summer, show that the ozone concentration decreases with increasing of the wind speed, due to the dynamics of the atmosphere, the mountain-valley circulation, the atmospheric fronts, etc. Additionally, the analysis of the distribution of ozone concentration against the wind directions demonstrates almost flat rate, which can be interpreted by the natural origin of the ozone at higher altitude and non-urban site. It does not allow us to consider the anthropogenic pollutants, mainly NOx and organic compounds, and their photochemical transformations as a contribution to the ozone concentration at the station Kopitoto.

\section{CONCLUSION}

Typical annual cycle of ozone concentration with summer maximum is observed for the Sofia region. The ozone concentration at the mountainous station is doubled than the urban area for all over the year.

Although the ground level ozone variability depends on many chemical and physical processes, here we evaluated only three parameters measured at automatic stations. The results from the correlation analysis show that the impact of air temperature on the ground level ozone concentration is clearly determined in autumn and summer. In the urban area, the air temperature relates to the pollutants' 
photochemical transformations (it is a direct effect of the solar radiation), whereas the wind speed and direction change the level of ozone by pollutants' transport, atmospheric turbulence, dispersion and accumulation of ozone. Most significant relation between ozone concentration and wind speed was obtained in the winter. The increasing of wind speed causes increase of ozone levels in the urban sites, but it decreases in the mountain.

In future, the study will be extended on the investigation of more meteorological parameters, anthropogenic activity and sources of NOx and VOCs emissions which will clarify the peculiarity of temporal distribution and variability of ozone concentration in urban area.

\section{REFERENCES}

1. Al-Jeelani, H.A. (2014), Diurnal and Seasonal Variations of Surface Ozone and Its Precursors in the Atmosphere of Yanbu, Saudi Arabia. J. Environ. Prot., 5, 408-422.

2. Atkinson R. (2000), Atmospheric chemistry of VOCs and NOx. Atmos. Environ. 34, $2063-2101$.

3. Dawson J. P., Adams P. J., Pandis S. N. (2007), Sensitivity of ozone to summer time climate in the eastern USA: A modeling case study. Atmos. Environ. 41, 1494-1511.

4. Donev E, Zeller K, Avramov A. (2002), Preliminary background ozone concentrations in the mountain and coastal areas of Bulgaria. Environ. Pollut., 117 (2), 281-286.

5. Elminir, H.K. (2005), Dependence of urban air pollutants on meteorology. Sci. Total Environ., 350, 225-237.

6. Filella I., Penuelas J. (2006), Daily, weekly and seasonal relationships among VOCs, NOx and O3 in a semi-urban area near Barcelona. J. Atmos. Chem, 54, 189201.

7. Grigorieva V., Kolev N., Donev E., Ivanov D., Mendeva B., Evgenieva Ts., Danchovski V., Kolev I. (2012), Surface and total ozone investigations in the region of Sofia, Bulgaria. Int. J. Remote Sens. 33 (11), 3542-3556.

8. Han S., Bian H., Feng Y., Liu A., Li X., Zeng F., Zhang X.. (2011), Analysis of the Relationship between $\mathrm{O}_{3}, \mathrm{NO}$ and $\mathrm{NO}_{2}$ in Tianjin, China. Aerosol Air Qual. Res., $11,128-139$.

9. Ivanov D., Lazarov D., Blagoev A., Danchovski V., Donev E., Wiman B.L.B. (2011), A seventy nine days' time series of Black Sea coastal ozone, aerosol, and meteorological parameters: statistical inter-relationships and implication. Bulgarian Geophysical Journal 37, 3-19.

10. Kalbarczyk R., Kalbarczyk E. (2009). Seasonal Variability of Tropospheric Ozone Concentration in Chosen Localities of North-western Poland Shaped by Meteorological Conditions. Ekológia (Bratislava). 28(3), 277-290.

11. Monks, P.S. (2000), A review of the observations and origins of the spring ozone maximum. Atmos. Environ. 34, 3545-3561.

12. Pudasainee D., Sapkota B., Shrestha M. L., Kaga A., Kondo A., Inoue Y. (2006), Ground level ozone concentrations and its association with NOx and meteorological parameters in Kathmandu valley, Nepal. Atmos. Environ., 40, 8081-8087. 
13. Rannik U., Mammarella I., Keronen P., Vesala T. (2009), Vertical advection and nocturnal deposition of ozone over a boreal pine forest. Atmos. Chem. Phys., 9, 2089-2095.

14. Rozbicka K., Rozbicki T. (2014), Spatio-temporal variations of tropospheric ozone concentrations in the Warsaw Agglomeration (Poland). Annals of Warsaw University of Life Sciences - SGGW, Land Reclamation, 46 (3), 247-261.

15. Senik I.A., Elansky N. F., Belikov I.B., Lisitsyna L.V., Galaktionov V.V., Kortunova Z. V. (2005), Main Patterns of the Temporal Variability of Surface Ozone in the Region of the Town of Kislovodsk at 870 and $2070 \mathrm{~m}$ above Sea Level, Izvestya, Atmospheric and Oceanic Physics, 41-1, 67-79.

16. Shao M., Zhang Y., Zeng L., Tang X., Zhang J., Zhong L., Wang B. (2009), Groundlevel ozone in the Pearl River Delta and the roles of VOC and NOx in its production. J. Environ. Management, 90, 512-518.

17. Tassev Y., Assenovski S., Donev E.,Ivanov D., Danchovski V. (2010), Comparative Analysis of Ground Level Ozone Distribution in Sofia and Plana Mountain during 2007 - 2009. Compt. Rend. Acad. Bulg. Sci., 63, 10, 1521-1532.

18. Topliiski, D. (2006), Climate of Bulgaria, Sofia, Amstels. pp 360. (in Bulgarian).

19. Wakamatsu S., I. Uno, T. Ohara, K. L. Schere. (1999), A study of the relationship between photochemical ozone and its precursor emissions of nitrogen oxides and hydrocarbons in Tokyo and surrounding areas. Atmos. Environ. 33, 3097-3108. 